Journal of Education and Teaching Learning (JETL)

Vol. 3, No. 1, 10-17 (2020)

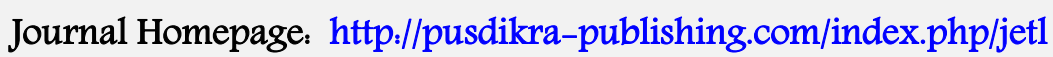

\title{
MENINGKATKAN EFEKTIFITAS MEMBACA WACANA DENGAN MENGGUNAKAN TEKNIK BACA SKIMMING PADA KOMPETENSI DASAR MENEMUKAN UNSUR-UNSUR DARI BUKU FIKSI DAN NONFIKSI YANG DIBACA MATA PELAJARAN BAHASA INDONESIA KELAS VII SMP NEGERI 7 PERCUT SEI TUAN TAHUN AJARAN 2016/2017
}

\author{
Heriana*) $^{*}$
}

\begin{abstract}
Abstrak
Subjek dalam penelitian ini adalah seluruh Kelas VII SMP Negeri 7 Percut Sei Tuan Tahun Ajaran $2016 / 2017$ berjumlah 32 orang siswa. Siklus I kecepatan membaca sebanyak 17 orang siswa (53,12 $\mathrm{Kpm})$ dengan kecepatan membaca tidak efektif dan 4 orang siswa $(12,5 \mathrm{Kpm})$ dengan kecepatan membaca cukup efektif dan 11 orang siswa $(24,37 \mathrm{Kpm})$ dengan kecepatan membaca efektif. Siklus II sebanyak 26 orang siswa $(81,25 \mathrm{Kpm})$ dengan kecepatan membaca efektif dan sebanyak 4 orang siswa $(12,5 \mathrm{Kpm})$ dengan kecepatan membaca cukup efektif dan 2 orang siswa $(6,25 \mathrm{Kpm})$ dengan kecepatan membaca tidak efektif. Pemahaman membaca siswa pada Siklus I sebanyak 11 orang siswa $(34,37 \%)$ mendapat kriteria nilai belajar sangat kurang, 6 orang siswa $(18,75 \%)$ mendapat kriteria nilai belajar kurang baik, 2 orang siswa $(6,25 \%)$ mendapat nilai kriteria nilai belajar cukup baik, 3 orang siswa $(9,37 \%)$ mendapat nilai kriteria baik dan 10 orang siswa $(31,25 \%)$ mendapat kriteria nilai belajar sangat baik. Siklus II sebanyak 4 orang siswa $(34,37 \%)$ mendapat kriteria nilai belajar sangat kurang, 3 orang siswa $(9,37 \%)$ mendapat kriteria nilai belajar kurang baik, 2 orang siswa $(6,25 \%)$ mendapat kriteria nilai belajar cukup baik, 7 orang siswa $(21,87 \%)$ mendapat kriteria nilai belajar baik dan 18 orang siswa $(56,25 \%)$ mendapat kriteria nilai belajar sangat baik. Berdasarkan hasil penelitian dapat diambil kesimpulan bahwa aktivitas siswa dalam kecepatan membaca wacana dengan menggunakan teknik baca skimmingdi SMP Negeri 7 Percut Sei Tuan berda pada kriteria Efektif. Dimana rata-rata kecepatan membaca siswa pada tes awal 119,28 Kpm, siklus I 154,12 Kpm, siklus II 217,75 Kpm. Sedangkan aktivitas siswa dalam pemahaman membaca wacana siswa pada tes awal $56,56 \%$, siklus | $69,37 \%$, siklus || $81,56 \%$.
\end{abstract}

Kata Kunci: Efektifitas Membaca, Teknik Baca Skimming

\section{PENDAHULUAN}

Bahasa adalah alat komunikasi utama dalam kehidupan. Kemampuan berbahasa itu pada mulanya dikuasai manusia tanpa disadari. Selanjutnya terjadi perkembangan perbendaharaan kata yang digunakan dalam berbahasa. Perkembangan itu terjadi melalui belajar sesuai dengan pengalaman yang dilalui setiap individu.

Keterampilan berbahasa dibagi menjadi empat aspek. Aspek-aspek bahasa tersebut antara lain keterampilan menyimak, berbicara, membaca dan menulis. Secara karakteristik, keempat keterampilan itu berdiri sendiri, namun dalam penggunaan bahasa sebagai proses komunikasi tidak

\footnotetext{
*) Penulis Adalah Guru SMP Negeri 7 Percut Sei Tuan
} 
dapat dipisahkan satu dengan yang lain. Misalnya, tidak mungkin ada orang menyimak tanpa ada yang berbicara, tidak mungkin ada orang membaca tanpa ada yang menulis dan sebaliknya.

Mulyono Abdurrahman (2003:4) Membaca merupakan aktivitas yang kompleks dengan mengarahkan sejumlah besar tindakan yang terpisah-pisah. Tindakan yang dimaksud adalah pembaca harus menggunakan pengertian, khayalan, mengamati dan mengingat-ngingat. Dalam proses memahami informasi dimaksud, kecepatan membaca sangat berperan untuk memperoleh informasi secara cepat.

Kecepatan membaca siswa dapat ditingkatkan dengan menggunakan salah satu dari 4 teknik tersebut, yaitu dengan teknik baca skimming, yang membutuhkan keterampilan membaca yang diatur secara sistematis untuk mendapatkan hasil yang efesien.

Dari pengalaman penulis saat mengadakan praktek lapangan, bahwa tidaklah semua pembaca khususnya siswa dapat memahami apa yang dibacanya. Hal ini diduga, karena ketidak tahuan pembaca terhadap faktor-faktor yang menetukan keberhasilan baca seseorang, seperti : faktor kesukaran bahan bacaan, faktor kesiapan, faktor lingkungan, faktor intelegensi, dan faktor teknik yang digunakan dalam membaca. Orang cenderung melakukan kegiatan membaca hanya melihat kata demi kata, frase demi frase, kalimat demi kalimat, bahkan paragraf demi paragraph tanpa berfikir bahwa ada suatu teknik membaca yang dapat mengarahkan mereka pada tujuan kegiatan membaca yang mereka lakukan.

Adapun penyebab siswa kurang memahami apa yang dibacanya menurut hasil pengamatan dan wawancara peneliti disebabkan kurang pengetahuan guru dalam menerapkan berbagai teknik membaca, terutama teknik baca skimming, atau cara guru yang kurang memperhatikan siswa atau adanya ketidaksesuaian antara wacana yang di sodorkan dengan tingkat dan kebutuhan siswa, juga merupakan masalah dalam meningkatkan kecepatan membaca anak didiknya, selain kurang nya kesadaran siswa akan kecepatan membacanya, juga disebabkan siswa belum pernah diberi latihan tentang teknik baca skimming ini.

Sesuai batasan masalah diatas, Maka rumusan masalah pada penelitian ini adalah. "Apakah dengan teknik baca skimming dapat meningkatkan efektifitas membaca wacana pada mata pelajaran Bahasa Indonesia Kelas VII SMP Negeri 7 Percut Sei Tuan T.A 2016/2017".

\section{METODE PENELITIAN}

Jenis Penelitian 
Jenis penelitian yang dipakai dalam penelitian ini adalah penelitian tindakan kelas. Dimana penelitian ini memiliki tujuan untuk meningkatkan dan memperbaiki proses pembelajaran yang seharusnya dilakukan oleh guru.

\section{Lokasi Penelitian dan Waktu Penelitian}

Penelitian ini dilaksanakan di SMP Negeri 7 Percut Sei Tuan Tahun Ajaran 2016/2017 dilaksanakan selama 3 bulan.

\section{Subjek dan Objek Penelitian}

Subjek dalam penelitian ini adalah seluruh siswa Kelas VII SMP Negeri 7 Percut Sei Tuan T.A 2016/2017 yang berjumlah 32 orang

Objek penelitian ini adalah teknik baca skimming untuk meningkatkan. Kecepatan membaca dan pemahaman siswa pada mata pelajaran Bahasa Indonesia.

\section{Prosedur Penelitian}

Pelaksanaan tindakan ini dilaksanakan selama 2 siklus yaitu siklus I dan siklus II. Pada siklus I dilaksanakan kegiatan pembelajaran sebanyak 1 kali pertemuan dan pada siklus II dilaksanakan kegiatan pembelajaran sebanyak 1 kali pertemuan. Hasil refleksi siklus I digunakan sebagai acuan dalam menentukan perbaikan tindakan pada siklus II. Sedangkan hasil refleksi siklus II nantinya.

\section{Teknik Analisis Data}

1. Untuk untuk mengukur kecepatan membaca, dilakukan langkah-langkah berikut: pertama, menghitung jumlah kata dalam wacana yang dibaca, dengan cara menghitung jumlah kata per baris dalam wacana dan dikalikan dengan jumlah baris wacana.

Misalnya:
a. Jumlah kata per baris rata-rata
$=12$
b. Jumlah baris yang dibaca
$=60$
c. Jumlah kata yang dibaca dalam wacana
$=12 \times 60=720$

Kedua, menghitung waktu tempuh baca, dengan cara mencatat waktu mulai membaca sampai waktu akhir membaca.

Misalnya:

1. Waktu mulai membaca: pukul 10.15 WIB

2. Waktu akhir membaca: pukul 10.20 WIB 
3. Waktu tempuh baca adalah 5 menit, yaitu dari pukul 10.15 WIB sampai dengan 10.20 WIB. Karena dalam rumus digunakan dalam detik. Maka menit diganti dengan detik, yaitu 5 menit dikalikan dengan 60 detik menjadi 300 detik.

Ketiga, menghitung kecepatan membaca. Kecepatan membaca terungkap dalam jumlah kata per menit (kpm). Untuk menghitung kpm ini, digunakan rumus yang dikemukakan soedarso (1996: 2) yaitu:

$\frac{\text { jumlah kata yang dibaca }}{\text { jumlah det } i k \text { untuk membaca }} \times 60=$ jumlah $\mathrm{Kpm}$

Kriteria Tingkat kecepatan membaca siswa

Tingkat kecepatan membaca siswa

Katagori

$$
\begin{array}{cr}
200-250 \mathrm{Kpm} & \text { Efektif } \\
110-190 \mathrm{Kpm} & \text { Cukup Efektif } \\
0-100 \mathrm{Kpm} & \text { Tidak Efektif }
\end{array}
$$

Keempat, menghitung persentase pemahanan siswa terhadap isi bacaan dengan rumus yang dikemukakan Harjasujana (1996: 68) yaitu: skor bobot tes pemahaman isi bacaan:

$\frac{\text { yang dapat dijawab dengan benar }}{\text { bobot / skorideal }} \times 100 \%=$

Kriteria penilaian aktivitas siswa :

$$
\begin{array}{ll}
85 \%-100 \% & \text { sangat baik } \\
75 \%-84 \% & \text { baik } \\
65 \%-74 \% & \text { cukup baik } \\
55 \%-64 \% & \text { kurang baik } \\
45 \%-54 \% & \text { sangat kurang } \quad \text {.......... (Kartiningrum, 2007) }
\end{array}
$$

2. Untuk mengetahui berapa persen tingkat keberhasilan yang ingin dicapai dengan menggunakan rumus:

$$
\begin{aligned}
& \mathrm{P}=\frac{f}{n} \times 100 \\
& \mathrm{P}=\text { angka prestasi } \\
& \mathrm{F}=\text { Jumlah siswa yang mengalami perubahan } \\
& \mathrm{N}=\text { jumlah seluruh siswa }
\end{aligned}
$$

\section{HASIL PENELITIAN DAN PEMBAHASAN}

Hasil penelitian yang dilakukan di SMP Negeri 7 Percut Sei Tuan bahwa kecepatan membaca dan pemahaman membaca wacana dengan teknik baca skimming dapat ditingkatkan. 
Berdasarkan hasil penelitian setelah diberikan tindakan siklus I diperoleh kecepatan membaca siswa dari 32 orang siswa sebanyak 17 orang siswa $(53,12 \mathrm{Kpm})$ dengan kecepatan membaca tidak efektif dan 4 orang siswa (12,5 Kpm) dengan kecepatan membaca cukup efektif dan 11 orang siswa (24,37 Kpm) dengan kecepatan membaca efektif. Pada siklus II diperoleh kecepatan membaca sebanyak 26 orang siswa $(81,25 \mathrm{Kpm})$ dengan kecepatan membaca efektif dan 4 orang siswa (12,5Kpm) dengan kecepatan membaca cukup efektif dan 2 orang siswa (6,25 Kpm)dengan kecepatan membaca tidak efektif. Dan pemahaman siswa pada siklus I dari 32 orang siswa sebanyak 11 orang siswa $(34,37 \%)$ mendapat kriteria nilai belajar sangat kurang, 6 orang siswa $(18,75 \%)$ mendapat kriteria niali belajar kurang baik, 2 orang siswa $(6,25 \%)$ mendapat nilai kriteria nilai belajar cukup baik, 3 orang siswa $(9,37 \%)$ mendapat niali kriteria baik dan 10 orang siswa $(31,25 \%)$ mendapat kriteia nilai belajar sangat baik, dan pada siklus II sebanyak 4 orang siswa $(34,37 \%)$ mendapat kriteria nilai belajar sangat kurang, 3 orang siswa $(9,37 \%)$ mendapat kriteria nilai belajar kurang baik, 2 orang siswa $(6,25 \%)$ mendapat kriteria nilai belajar cukup baik 7 orang siswa $(21,87 \%)$ mendapat kriteria nilai belajar baik dan 18 orang siswa $(56,25 \%)$ mendapat kriteria nilai belajar sangat baik.

Tabel 1. Daftar Nilai Kecepatan Membaca Tes Awal, Siklus I, Siklus II

\begin{tabular}{|c|c|c|c|c|c|}
\hline No & $\begin{array}{c}\text { Nomor } \\
\text { Responden }\end{array}$ & Tes Awal & Siklus I & Siklus II & Keterangan \\
\hline 1 & $S_{1}$ & $50 \mathrm{Kpm}$ & $50 \mathrm{Kpm}$ & $250 \mathrm{Kpm}$ & Meningkat \\
\hline 2 & $\mathrm{~S}_{2}$ & $100 \mathrm{Kpm}$ & $125 \mathrm{Kpm}$ & $250 \mathrm{Kpm}$ & Meningkat \\
\hline 3 & $\mathrm{~S}_{3}$ & $100 \mathrm{Kpm}$ & $100 \mathrm{Kpm}$ & $250 \mathrm{Kpm}$ & Meningkat \\
\hline 4 & $\mathrm{~S}_{4}$ & $100 \mathrm{Kpm}$ & $100 \mathrm{Kpm}$ & $167 \mathrm{Kpm}$ & Meningkat \\
\hline 5 & $\mathrm{~S}_{5}$ & $100 \mathrm{Kpm}$ & $100 \mathrm{Kpm}$ & $125 \mathrm{Kpm}$ & Meningkat \\
\hline 6 & $\mathrm{~S}_{6}$ & $100 \mathrm{Kpm}$ & $100 \mathrm{Kpm}$ & $250 \mathrm{Kpm}$ & Meningkat \\
\hline 7 & $\mathrm{~S}_{7}$ & $100 \mathrm{Kpm}$ & $100 \mathrm{Kpm}$ & $167 \mathrm{Kpm}$ & Meningkat \\
\hline 8 & $\mathrm{~S}_{8}$ & $100 \mathrm{Kpm}$ & $100 \mathrm{Kpm}$ & $250 \mathrm{Kpm}$ & Meningkat \\
\hline 9 & $\mathrm{~S}_{9}$ & $100 \mathrm{Kpm}$ & $100 \mathrm{Kpm}$ & $250 \mathrm{Kpm}$ & Meningkat \\
\hline 10 & $\mathrm{~S}_{10}$ & $100 \mathrm{Kpm}$ & $100 \mathrm{Kpm}$ & $250 \mathrm{Kpm}$ & Meningkat \\
\hline 11 & $\mathrm{~S}_{11}$ & $167 \mathrm{Kpm}$ & $125 \mathrm{Kpm}$ & $250 \mathrm{Kpm}$ & Meningkat \\
\hline 12 & $\mathrm{~S}_{12}$ & $250 \mathrm{Kpm}$ & $250 \mathrm{Kpm}$ & $250 \mathrm{Kpm}$ & Tetap \\
\hline 13 & $\mathrm{~S}_{13}$ & $50 \mathrm{Kpm}$ & $100 \mathrm{Kpm}$ & $167 \mathrm{Kpm}$ & Meningkat \\
\hline 14 & $\mathrm{~S}_{14}$ & $100 \mathrm{Kpm}$ & $100 \mathrm{Kpm}$ & $250 \mathrm{Kpm}$ & Meningkat \\
\hline 15 & $\mathrm{~S}_{15}$ & $100 \mathrm{Kpm}$ & $125 \mathrm{Kpm}$ & $250 \mathrm{Kpm}$ & Meningkat \\
\hline 16 & $\mathrm{~S}_{16}$ & $125 \mathrm{Kpm}$ & $250 \mathrm{Kpm}$ & $250 \mathrm{Kpm}$ & Tetap \\
\hline
\end{tabular}




\begin{tabular}{|c|c|c|c|c|c|}
\hline 17 & $S_{17}$ & $250 \mathrm{Kpm}$ & $167 \mathrm{Kpm}$ & $250 \mathrm{Kpm}$ & Meningkat \\
\hline 18 & $\mathrm{~S}_{18}$ & $250 \mathrm{Kpm}$ & $250 \mathrm{Kpm}$ & $250 \mathrm{Kpm}$ & Tetap \\
\hline 19 & $\mathbf{S}_{19}$ & $250 \mathrm{Kpm}$ & $250 \mathrm{Kpm}$ & $250 \mathrm{Kpm}$ & Tetap \\
\hline 20 & $\mathrm{~S}_{20}$ & $100 \mathrm{Kpm}$ & $250 \mathrm{Kpm}$ & $250 \mathrm{Kpm}$ & Tetap \\
\hline 21 & $S_{21}$ & $50 \mathrm{Kpm}$ & $100 \mathrm{Kpm}$ & $125 \mathrm{Kpm}$ & Meningkat \\
\hline 22 & $S_{22}$ & $50 \mathrm{Kpm}$ & $250 \mathrm{Kpm}$ & $250 \mathrm{Kpm}$ & Tetap \\
\hline 23 & $\mathrm{~S}_{23}$ & $50 \mathrm{Kpm}$ & $100 \mathrm{Kpm}$ & $100 \mathrm{Kpm}$ & Tetap \\
\hline 24 & $\mathrm{~S}_{24}$ & $100 \mathrm{Kpm}$ & $100 \mathrm{Kpm}$ & $100 \mathrm{Kpm}$ & Tetap \\
\hline 25 & $\mathrm{~S}_{25}$ & $100 \mathrm{Kpm}$ & $250 \mathrm{Kpm}$ & $250 \mathrm{Kpm}$ & Tetap \\
\hline 26 & $\mathrm{~S}_{26}$ & $100 \mathrm{Kpm}$ & $250 \mathrm{Kpm}$ & $250 \mathrm{Kpm}$ & Tetap \\
\hline 27 & $\mathrm{~S}_{27}$ & $100 \mathrm{Kpm}$ & $100 \mathrm{Kpm}$ & $250 \mathrm{Kpm}$ & Meningkat \\
\hline 28 & $\mathrm{~S}_{28}$ & $125 \mathrm{Kpm}$ & $250 \mathrm{Kpm}$ & $250 \mathrm{Kpm}$ & Tetap \\
\hline 29 & $\mathrm{~S}_{29}$ & $250 \mathrm{Kpm}$ & $250 \mathrm{Kpm}$ & $250 \mathrm{Kpm}$ & Tetap \\
\hline 30 & $\mathrm{~S}_{30}$ & $100 \mathrm{Kpm}$ & $100 \mathrm{Kpm}$ & $250 \mathrm{Kpm}$ & Meningkat \\
\hline 31 & $\mathrm{~S}_{31}$ & $100 \mathrm{Kpm}$ & $100 \mathrm{Kpm}$ & $167 \mathrm{Kpm}$ & Meningkat \\
\hline 32 & $\mathrm{~S}_{32}$ & $100 \mathrm{Kpm}$ & $250 \mathrm{Kpm}$ & $250 \mathrm{Kpm}$ & Tetap \\
\hline \multicolumn{2}{|c|}{ Jumlah } & 3817 Kpm & $4932 \mathrm{Kpm}$ & $6968 \mathrm{Kpm}$ & \\
\hline \multicolumn{2}{|c|}{ Rata-rata } & $119,28 \mathrm{Kpm}$ & $154,12 \mathrm{Kpm}$ & $217,75 \mathrm{Kpm}$ & \\
\hline
\end{tabular}

Tabel 2. Daftar Persentase Nilai Tes Pemahaman Membaca Tes Awal, Siklus I, Siklus II

\begin{tabular}{|c|c|c|c|c|c|}
\hline NO & $\begin{array}{c}\text { Nomor } \\
\text { Responden }\end{array}$ & Tes Awal & Siklus I & Siklus II & Keterangan \\
\hline 1 & S1 & 40 & 60 & 80 & Meningkat \\
\hline 2 & S2 & 60 & 70 & 90 & Meningkat \\
\hline 3 & S3 & 50 & 60 & 80 & Meningkat \\
\hline 4 & S4 & 10 & 20 & 60 & Meningkat \\
\hline 5 & S5 & 40 & 40 & 40 & Tetap \\
\hline 6 & S6 & 60 & 60 & 80 & Meningkat \\
\hline 7 & S7 & 60 & 60 & 70 & Meningkat \\
\hline 8 & $S 8$ & 40 & 60 & 80 & Meningkat \\
\hline 9 & $S 9$ & 20 & 20 & 80 & Meningkat \\
\hline 10 & $S 10$ & 50 & 50 & 80 & Meningkat \\
\hline 11 & $S 11$ & 70 & 80 & 90 & Meningkat \\
\hline 12 & $S 12$ & 100 & 100 & 100 & Tetap \\
\hline 13 & $S 13$ & 60 & 60 & 70 & Meningkat \\
\hline 14 & $S 14$ & 50 & 50 & 80 & Meningkat \\
\hline 15 & $S 15$ & 40 & 70 & 90 & Meningkat \\
\hline 16 & $S 16$ & 70 & 90 & 100 & Meningkat \\
\hline 17 & $S 17$ & 90 & 80 & 90 & Meningkat \\
\hline 18 & $S 18$ & 90 & 90 & 100 & Meningkat \\
\hline 19 & $S 19$ & 90 & 90 & 90 & Tetap \\
\hline
\end{tabular}




\begin{tabular}{|c|c|c|c|c|c|}
\hline 20 & S20 & 60 & 100 & 100 & Tetap \\
\hline 21 & S21 & 30 & 50 & 90 & Meningkat \\
\hline 22 & S22 & 60 & 90 & 90 & Meningkat \\
\hline 23 & S23 & 0 & 0 & 50 & Meningkat \\
\hline 24 & S24 & 40 & 50 & 60 & Meningkat \\
\hline 25 & S25 & 60 & 90 & 100 & Meningkat \\
\hline 26 & S26 & 60 & 100 & 100 & Tetap \\
\hline 27 & S27 & 60 & 60 & 90 & Meningkat \\
\hline 28 & S28 & 80 & 80 & 90 & Meningkat \\
\hline 29 & S29 & 90 & 90 & 100 & Meningkat \\
\hline 30 & S30 & 40 & 60 & 90 & Meningkat \\
\hline 31 & S31 & 20 & 40 & 60 & Meningkat \\
\hline 32 & S32 & 60 & 100 & 100 & Tetap \\
\hline \multicolumn{2}{|c|}{ Jumlah } & 1810 & 2120 & 2610 & Meningkat \\
\hline \multicolumn{2}{|c|}{ Rata-rata } & $56,56 \%$ & $69,37 \%$ & $81,56 \%$ & \\
\hline
\end{tabular}

Tabel 3. Rekapitulasi Kecepatan Membaca dan Pemahaman Wacana

\begin{tabular}{|c|l|c|}
\hline \multirow{2}{*}{ No } & \multicolumn{1}{|c|}{ Deskripsi Nilai } & Nilai Kecepatan Membaca \\
\cline { 2 - 3 } & \multicolumn{2}{|c|}{} \\
\hline 1 & Tes Awal & $119,28 \mathrm{Kpm}$ \\
\hline 2 & Siklus I & $154,12 \mathrm{Kpm}$ \\
\hline 3 & Siklus I & $217,75 \mathrm{Kpm}$ \\
\hline \multicolumn{3}{|c|}{ Nilai Pemahaman } \\
\hline 1 & Tes Awal & $56,56 \%$ \\
\hline 2 & Siklus I & $69,37 \%$ \\
\hline 3 & Siklus II & $81,56 \%$ \\
\hline
\end{tabular}

Berdasarkan data di atas dapat dilihat bahwa hasil siswa mengalami peningkatan. Jadi dapat disimpulkan bahwa dengan Teknik baca skimming dalam kecepatan membaca dan pemahaman wacana pada saat pembelajaran berhasil. Hal ini dapat dilihat dari hasil penelitian yang menunjukkan bahwa semua siswa mengalami peningkatan nilai.

\section{KESIMPULAN}

1. Aktivitas siswa dalam kecepatan membaca wacana dengan menggunakan teknik baca skimmingdi SMP Negeri 7 Percut Sei Tuan berada pada kriteria Efektif. Dimana rata-rata kecepatan membaca siswa pada tes awal 119,28 Kpm, siklus | 154,12 Kpm, siklus II 217,75 Kpm.

2. Aktivitas siswa dalam pemahaman membaca wacana dengan menggunakan teknik baca skimming di SMP Negeri 7 Percut Sei Tuan berada pada kriteria nilai belajar baik. Di mana rata-rata pemahaman siswa pada tes awal $56,56 \%$, siklus I 69,37 \%, siklus II $81,56 \%$.

\section{DAFTAR PUSTAKA}

Abdurrahman, Mulyono. 2003. Pendidikan Bagi Anak Berkesulitan Belajar, Jakarta: Rineka Cipta. 
MENINGKATKAN EFEKTIFITAS MEMBACA WACANA DENGAN MENGGUNAKAN TEKNIK BACA SKIMMING PADA

KOMPETENSI DASAR MENEMUKAN UNSUR-UNSUR DARI BUKU FIKSI DAN NONFIKSI YANG DIBACA MATA

PELAJARAN BAHASA INDONESIA KELAS VII SMP NEGERI 7 PERCUT SEI TUAN TAHUN AJARAN 2016/2017

Arikunto, Suharsimi. 2006. Penelitian Tindakan Kelas, Jakarta: Bumi Aksara.

Isjoni. 2009. Efektivitas Pembelajaran. Bandung : Alfabeta.

Rahim, Farida 2008. Sistem Membaca Cepat Dan Efektif. Jakarta : Bumi Aksara.

Said. 2009. Efektivitas Pembelajaran, Bandung : Penerbit Angkasa.

Syamsuddin. 2001. Studi Wacana Bahasa Indonesia. Jakarta : Depdikbud.

Warsita 2008. Efektivitas. Jakarta : Bumi Aksara.

Zaini, M. F. (2019). The Implementation Of Learning Management In Class VIII Madrasa Tsanawiyah Islamiyah (Mts) Ypi Batangkuis. International Conference on Islamic Educational Management (ICIEM). 